
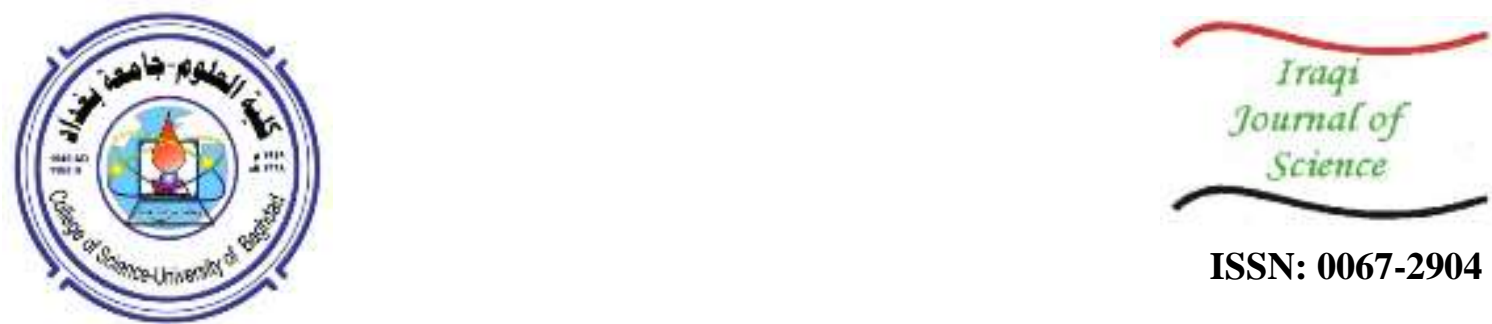

ISSN: 0067-2904

\title{
Seroprevalence of Toxoplasmosis in patients with chronic liver disease in Baghdad
}

\author{
Raghad Hasan Nafal ${ }^{1}$, Harith Saeed Al-Warid ${ }^{1 *}$, Hayder Jamal Al-Sultan ${ }^{2}$ \\ ${ }^{1}$ Department of Biology, College of Science, University of Baghdad, Baghdad, Iraq \\ ${ }^{2}$ Gastroenterology and Hepatology Teaching Hospital, Medical city, Ministry of Health and Environment, \\ Baghdad, Iraq
}

\begin{abstract}
The influence of Toxoplasma gondii in the pathogenesis of hepatic disease has lately had considerable attention. The objective of this study is to assess the seroprevalence of $T$. gondii infection in patients with chronic liver disease from Baghdad-Iraq. All patients have attended Gastroenterology and Hepatology Teaching Hospital, Medical city in Baghdad, Iraq An analytical case-control study was achieved from September to November 2018. Seventy male patients with chronic liver disease (CLD) and 70 control males (free of chronic liver diseases) participated in this study, their ages were between (18-80) years old. Serum samples were taken from all subjects and were analysed with enzyme-linked immunosorbent assay (ELISA) for the presence of anti-T.gondii IgG and IgM antibodies. The prevalence of anti-T.gondii IgG was significantly higher $62.85 \%$ in CLD patients compared with $27.28 \%$ in the control subjects. Anti-T. gondii IgM antibodies were also showed to be significantly higher in CLD patients compared with control subjects. A significant relation between age and the prevalence of T.gondii was reported in this study. Toxoplasmosis was largely reported among those aged $(>40)$ years old for both CLD patients and control subjects, while the other age groups showed less seroprevalence rates.

Sera samples for both CLD patients and control subjects were tested for different liver enzyme: aspartate aminotransferase (AST), alanine aminotransferase (ALT), and alkaline phosphatase (ALP). ALT was greater in CLD-Toxoplasma positive patients comparing to CLD-Toxoplasma negative patients. In addition to AST was higher in control-Toxoplasma positive subjects comparing to control-Toxoplasma negative subjects.

These findings show that Toxoplasmosis is high expected to be diagnosed with chronic liver disease patients. Consequently, attention would be focused on health education of peoples at high risk of toxoplasmosis.
\end{abstract}

Keywords: Liver disease, Liver enzymes, Toxoplasmosis, Iraq.

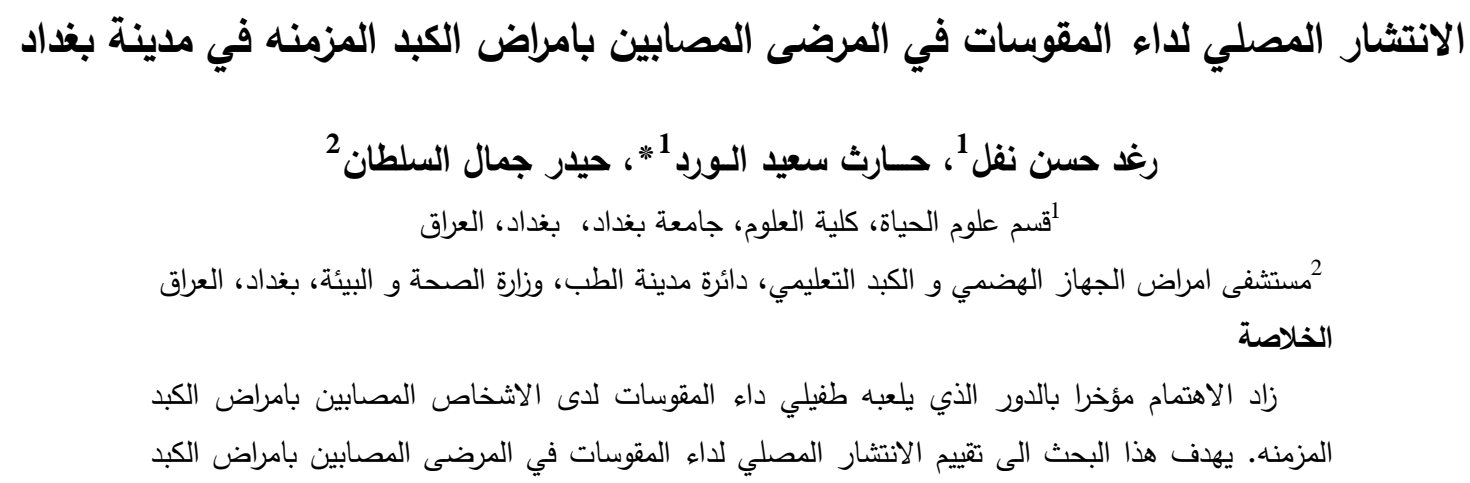

*Email: harithalward@scbaghdad.edu.iq 


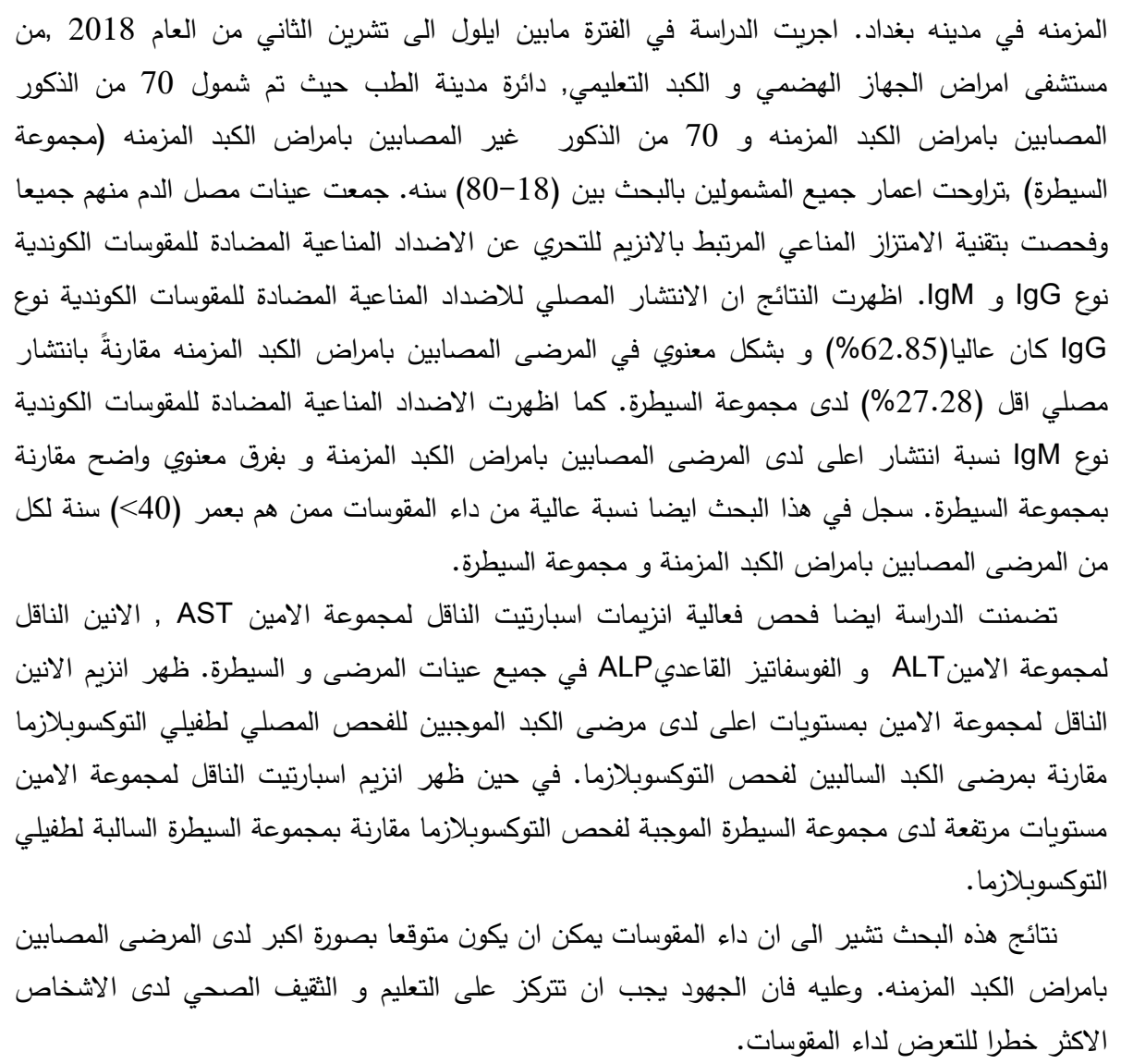

\section{Introduction}

Toxoplasmosis is an infection caused by Toxoplasma gondii, a member of the Apicomplexa phylum. Toxoplasmosis is a cosmopolitan infection of humans and other warm-blooded animals. This protozoan parasite is a pathogen of public health and economic concern [1]. Infections initiated by $T$. gondii remain to inflict important public health difficulties since it can cause different clinical aspects such as retino-choroiditis, hydrocephaly, mental retardation, and even death in fetus and lifethreatening encephalitis in individuals with AIDS, organ transplant recipients, or receiving immunosuppressive therapy [2,3]. Globally, it was estimated that between $30 \%$ and $65 \%$ of all people worldwide are infected with T.gondii. Seroprevalence of T.gondii infection in human increases with age but it does not differ significantly between sexes, and is lower in cold regions, hot and arid areas, or at high elevations [4].

Though T. gondii has neurotropic and ocular affinities, this parasite can also infect additional organs, such as liver, pancreas, spleen, heart, and lymph nodes [5]. Some comparatively small researches have noticed link between $T$. gondii infection and various aspects of liver pathologies, such as hepatomegaly, granuloma, hepatitis, necrosis, jaundice, and cirrhosis [6-10]. T. gondii infection has also been associated to irregular liver function, it can affect the functions of liver enzymes [11, 12]. Recently, concern in evaluating the association between $T$. gondii infection and liver disease has amplified [13, 14], possibly because of the massive worldwide burden and public health impacts of both toxoplasmosis [15] and liver diseases [16]. As significant results exist relating Toxoplasmosis to liver impairment, and there are no existing information about the correlation between toxoplasmosis and liver diseases in Iraq. It is important to recognize some approval connecting $T$. gondii infection to liver disease in Iraq. So, the current study was conducted to assess the seroprevalence of $T$. gondii infection in patients suffered from chronic liver disease from Baghdad-Iraq using enzyme-linked immunosorbent assay (ELISA).

\section{Materials and Methods Study design subject}

This research is an analytical case control study conducted from September to November 2018.The population in this study was adult male patients with chronic liver disease and adult male healthy control subjects. This study was designed to evaluate the relationship of chronic liver disease with $T$. 
gondii infection. Seventy outpatients attended in Gastroenterology and Hepatology Teaching Hospital, Medical city in Baghdad, Iraq participated in this research. All patients were diagnosed as chronic liver disease patients (CLD) based on some clinical and biochemical examinations which were done by GIT consultant. The mean age of the CLD patients was 50.11 \pm 14.72 years (range: 18-80 years). All patients were from Baghdad except some from other governorates, Diyala $(n=3)$, Anbar $(n=1)$, Babil $(n=1)$ and Al Muthanna $(n=1)$. The causes of liver disease was varied among the CLD patients, the majority was alcohol consumption $(n=29)$, hepatitis $C$ virus $(n=15)$, Wilson disease $(n=2)$ and unknown cause $(\mathrm{n}=28)$.

Seventy control individuals (no chronic liver diseases) were also involved in the study. The mean age in control subjects was $51.97 \pm 10.87$ (range: 18-71). The healthy control subjects were obtained from the general population of Baghdad, Iraq. This study protocol was approved by Ministry of Health and Environment, Baghdad, Iraq. A permission from all patients and healthy control subjects were also approved.

\section{Detection of the anti-T. gondii IgG and anti-T. gondii IgM}

Serum samples of both CLD patients and control subjects were taken and reserved frozen at $-20^{\circ} \mathrm{C}$ until analysed. They were analysed for anti-T. gondii IgG antibodies with the enzyme immunoassay kit "Toxoplasma IgG" (Humman). Anti-T. gondii IgG antibody levels were stated as International Units (IU)/ml, and a result equivalent or greater than $8 \mathrm{IU} / \mathrm{ml}$ was considered positive. In addition, sera positive for anti-T. gondii IgG antibodies were further analyzed for anti-T. gondii IgM antibodies by the commercially available enzyme immunoassay "Toxoplasma IgM" kit (Humman). All tests were achieved after the directions of the manufacturer.

\section{Biochemical tests}

Sera samples for both CLD patients and control subjects were analysed for different liver enzymes using kits for aspartate aminotransferase (AST), alanine aminotransferase (ALT) (Randox Laboratories Ltd., Antrim, UK), and alkaline phosphatase (ALP) (BioMerieux, Lyon, France) according to the manufacturer's instructions.

\section{Child-Pugh calculation}

Child-Pugh was used to evaluate the prognosis of chronic liver disease and cirrhosis and its relation with toxoplasmosis. Child-pugh was calculated by a calculator found in https://www.mdcalc.com/child-pugh-score-cirrhosis-mortality.

\section{Statistical Analysis}

The results were stated as percentage and mean \pm standard deviation (SD). Data analysis was achieved by SPSS 16.0 (SPSS Inc., Chicago, IL, USA).The data were assessed by chi-square test and the Student's t-test $(\mathrm{t})$. P values $<0.05$ were considered statistically significant.

\section{Results}

Results showed that the Anti-T. gondii IgG antibodies were significantly higher in CLD patients comparing with control subjects. Anti-T. gondii IgG antibodies were found in $44(62.85 \%)$ of 70 CLD patients and in $17(24.28 \%)$ of 70 controls $(\mathrm{P}=0.00000418)$.Of the 44 anti-T. gondii $\mathrm{IgG}$ positive patients, $22(50 \%)$ had IgG levels higher than $100 \mathrm{IU} / \mathrm{ml}$, and 22(50\%) between 7 to $99 \mathrm{IU} / \mathrm{ml}$. In comparison, of the 17anti-T. gondii IgG positive controls, 6(35.29\%) had IgG levels greater than 100 $\mathrm{IU} / \mathrm{ml}$ and $11(64 \%)$ between 7 to $99 \mathrm{IU} / \mathrm{ml}$. Anti-T. gondii IgM antibodies were also found significantly higher in CLD patient comparing with control subjects. Anti-T. gondii IgM antibodies were detected in $35(50 \%)$ of 70 patients and in $7(10 \%)$ of 70 control subjects $(\mathrm{P}=0.00000024)$.

Child-Pugh scoring system was calculated to evaluate the prognosis of liver cirrhosis in CLD patients. The majority of Toxoplasma seropositive - CLD patients were reported in class-C (Table-1), although no significant relation $(\mathrm{p}>0.05)$ was noticed between the child-Pugh classes and the seroprevalence of T.gondii.

Table-2 illustrates the seroprevalence based on patients' age. CLD patients showed high seroprevalence rate of T.gondii in all age groups. The highest seroprevalence of $T$. gondii infection was $88.2 \%$ which reported in CLD patiennts whose ages were less than 40 years, while the other age groups showed less seroprevalence rates (Table-2). The statistical analysis showed significant relation between age and seroprevalence of T.gondii in both CLD patients and control subjects $(p<0.05)$.

The results of liver enzymes for both CLD patients and control group are illustrated in Table-3. Results showed a non-significant participated ( $p>0.05)$ of the liver enzymes: AST, ALT, and ALP in the sera of positive T.gondii and negative patients. Although ALT was grater in CLD-T.gondii positive 
patients comparing to CLD-T.gondii negative patients. As well as AST was higher in controlToxoplasma positive subjects comparing to control-Toxoplasma negative subjects.

Table 1-Prevalence of Toxoplasm gondii related to age for CLD patients and Control group

\begin{tabular}{|c|c|c|c|c|c|c|c|}
\hline & \multicolumn{3}{|c|}{ Cases with liver diseases } & \multicolumn{3}{|c|}{ Control group } & \\
\hline $\begin{array}{c}\text { Age } \\
\text { group/years }\end{array}$ & $\begin{array}{l}\text { No. of } \\
\text { tested }\end{array}$ & $\begin{array}{l}\text { No. of } \\
\text { positive }\end{array}$ & $\begin{array}{c}\text { Prevalence of } \\
\text { T.gondii }(\%)\end{array}$ & $\begin{array}{l}\text { No. of } \\
\text { tested }\end{array}$ & $\begin{array}{l}\text { No. of } \\
\text { positive }\end{array}$ & $\begin{array}{c}\text { Prevalence of } \\
\text { T.gondii }(\%)\end{array}$ & $\begin{array}{c}\text { P- } \\
\text { value }\end{array}$ \\
\hline$>\mathbf{4 0}$ & 17 & 15 & 88.2 & 9 & 3 & 33.3 & 0.0039 \\
\hline $41-50$ & 17 & 10 & 58.8 & 22 & 6 & 27.27 & 0.011 \\
\hline $51-60$ & 16 & 8 & 50 & 22 & 4 & 18.18 & 0.037 \\
\hline$<60$ & 20 & 11 & 55 & 17 & 4 & 23.52 & 0.051 \\
\hline
\end{tabular}

Table 2-Child -Pugh score of CLD patients according to Toxoplasma gondii seroprevalence

\begin{tabular}{|c|c|c|}
\hline & \multicolumn{2}{|c|}{ CLD patients } \\
\hline Child-Pugh Class & $\begin{array}{c}\text { Toxoplasma + ve n(\%) } \\
\mathbf{n = 4 5}\end{array}$ & $\begin{array}{c}\text { Toxoplasma-ve n(\%) } \\
\mathbf{n = 2 5}\end{array}$ \\
\hline Child B & $22(48.8 \%)$ & $11(44 \%)$ \\
\hline Child C & $23(51.11 \%)$ & $14(56 \%)$ \\
\hline
\end{tabular}

Table 3-Effects Toxoplasma gondii infection on the levels of liver enzymes in chronic liver disease patients and control subjects.

\begin{tabular}{|c|c|c|c|c|}
\hline \multirow[b]{2}{*}{ Liver Enzymes } & \multicolumn{2}{|c|}{ CLD patients } & \multicolumn{2}{|c|}{ Control } \\
\hline & Toxoplasma + ve & Toxoplasma-ve & Toxoplasma + ve & Toxoplasma - ve \\
\hline $\begin{array}{l}\text { ALP IU/L } \\
\text { (95\% CI) }\end{array}$ & $176.7(127.9-225.5)$ & $185(119.9-250.8)$ & 90 (74.47- 105.4) & $91.6(82.84-100.4)$ \\
\hline $\begin{array}{c}\text { ALT IU/L } \\
(95 \% \mathrm{CI}) \\
\end{array}$ & $51.62(41.34-61.9)$ & $40.12(26.33-53.9)$ & $39(33.74-47.79)$ & $43.66(39.68-47.64)$ \\
\hline $\begin{array}{c}\text { AST IU/L (95\% } \\
\text { CI) }\end{array}$ & $67.66(55.54-80.01)$ & $\begin{array}{c}69.32(52.91- \\
85.73)\end{array}$ & $28.2(24.96-31.39)$ & $26.9(25.12-2876)$ \\
\hline
\end{tabular}

\section{Discussion}

Toxoplasma gondii infections exhibits variable clinical aspects. Assessment of its prevalence in some risk groups in the community and founding of these risk groups act an important part in preparing the required precautions against this protozoal infection[17].In the current study Toxoplasma ELISA antibody positivity was significantly greater in chronic liver disease patients. A higher incidence of anti- $T$. gondii IgG and IgM antibodies was reported in CLD patients than control group. Studies regarding the link of $T$. gondii infection in liver disease patients in Iraq are very limited. The high level of anti-T. gondii IgM and IgG levels in CLD patients than in control group may be explained by the declining of cell-mediated and humoral immune response in chronically infected patients due to subsequent reactivation of latent infection[18, 19]. Our results agrees with that stated by Ghanam et al [20]who reported high seroprevalence (65.5\%) of $T$. gondii antibodies in patients with acute and chronic liver diseases against a $27 \%$ seroprevalence found in the group of healthy control subjects. Our results also agreed with other investigators who stated an association of Toxoplasmosis with liver diseases [21,22]. On other hand our results disagreed with those illustrated by Alvarado-Esquivel, et al. [23] who did not show any link between seropositivity to $T$. gondii and liver diseases with comparable seroprevalence of $T$. gondii IgM and IgG levels in CLD patients and control subjects. Undoubtedly, differences in the features of the studies could clarify the dissimilarities in the seroprevalences including the use of dissimilar laboratory approaches, difference in sex and ages of participants and sample size of CLD patients and control subjects. In this study the majority of 
Toxoplasma seropositive - CLD patients were reported in class $\mathrm{C}$ this result agreed with the findings of El-Henawy et al. [24] who presented that the majority of Toxoplasma seropositive cases were class C.

Toxoplasmosis was largely reported among those aged $(>40)$ years old for both CLD patients and control subjects, while the other age groups showed less seroprevalence rates. The reduction in seroprevalence with age is likely to be a function of the development of immunity induced by previous infections [25].

Liver enzyme activities are good indicators of liver cell injury. Generally, these enzymes are found in the liver and other tissues where they function in energy metabolism involving the transamination of amino acids. Nevertheless, in cases of impairment in liver cells, AST and ALT might drop out into the general circulation leading to elevated activity [26]. Liver injury is a well-established complication of acute T.gondii infections, as this infection can cause cell infiltration especially in the portal areas[27]. Furthermore, protein fractions of ALT and AST diverse according to the strength of inflammation provoked by T.gondii infection. In the current study, ALT was higher in CLDToxoplasma positive patients comparing to CLD-Toxoplasma negative patients. In addition to AST was higher in control-Toxoplasma positive subjects comparing to control-Toxoplasma negative subjects. These results agreed with the results of Limdi and Hyde [28] and Mahmood and Dawood [29]. This results might be described by the presence of $T$. gondii in some liver tissue parts like the cells of bile duct, meanwhile hepatic ALP is known to be found on the canalicular and luminal portions on the bile duct epithelial tissue [28].From the previously mentioned results, it is likely to conclude that patients suffering from chronic liver diseases are susceptible to toxoplasmosis as showed by Toxoplasma seropositivity. Consequent evolution of liver pathology and development of some complications such as cirrhosis must be measured. More comprehensive studies are needed to address this issue in Iraq.

\section{References}

1. Holec-Gąsior, L. and Kur, J. 2010. Toxoplasma gondii: Recombinant GRA5 antigen for detection of immunoglobulin $\mathrm{G}$ antibodies using enzyme-linked immunosorbent assay. Experimental parasitology, 124(3): 272-278.

2. Zeleke, A.J. and Melsew, Y.A. 2017. Seroprevalence of Toxoplasma gondii and associated risk factors among HIV-infected women within reproductive age group at Mizan Aman General Hospital, Southwest Ethiopia: a cross sectional study. BMC research notes, 10(1):70.

3. Elsheikha, H.M. 2008. Congenital toxoplasmosis: priorities for further health promotion action. Public health, 122(4): 335-353.

4. Montoya JG. and Liesenfeld O. 2004. Toxoplasmosis. Lancet, 363: 1965-1976.

5. Snydman, D.R., Walker, M. and Zunt, J.R. 2005. Parasitic central nervous system infections in immunocompromised hosts. Clinical Infectious Diseases, 40(7): 1005-1015.

6. Weitberg, A.B., Alper, J.C., Diamond, I. and Fligiel, Z. 1979. Acute granulomatous hepatitis in the course of acquired toxoplasmosis. New England Journal of Medicine, 300(19): 1093-1096.

7. Botterel, F., Ichai, P., Feray, C., Bouree, P., Saliba, F., Raspa, R.T., Samuel, D. and Romand, S., 2002. Disseminated toxoplasmosis, resulting from infection of allograft, after orthotopic liver transplantation: usefulness of quantitative PCR. Journal of clinical microbiology, 40(5):1648-1650.

8. Karasawa, T., Shikata, T., Takizawa, I., Morita, K. and Komukai, M., 1981. Localized hepatic necrosis related to cytomegalovirus and Toxoplasma gondii. Pathology International, 31(3): 527534.

9. Ustun, S., Aksoy, U., Dagci, H. and Ersoz, G. 2004. Frequency of toxoplasmosis in patients with cirrhosis. World journal of gastroenterology, 10(3): 452.

10. Shapira, Y., Agmon-Levin, N., Renaudineau, Y., Porat-Katz, B.S., Barzilai, O., Ram, M., Youinou, P. and Shoenfeld, Y. 2012. Serum markers of infections in patients with primary biliary cirrhosis: evidence of infection burden. Experimental and molecular pathology, 93(3): 386-390.

11. Ortego, T.J., Robey, B., Morrison, D. and Chan, C. 1990. Toxoplasmic chorioretinitis and hepatic granulomas. American Journal of Gastroenterology, 85(10): 1418-1420.

12. Al-Jowari, S.A.K. and Hussein, D.K. 2014. Effect of toxoplasmosis infection on liver and kidney functions among pregnant women in Abo-Gharib district-Iraq. Iraqi Journal of Science, 55(1): 101-105. 
13. El-Sayed, N., Ramadan, M. and Ramadan, M. 2016. Toxoplasma gondii infection and chronic liver diseases: evidence of an association. Tropical medicine and infectious disease, 1(1): 7.

14. Huang, J., Zhang, H., Liu, S., Wang, M., Wan, B., Velani, B., Zhu, Y. and Lin, S. 2018. Is Toxoplasma gondii infection correlated with nonalcoholic fatty liver disease?-a population-based study. BMC infectious diseases, 18(1): 629.

15. Al Hamada, A., Habib, I., Barnes, A. and Robertson, I. 2019. Risk factors associated with seropositivity to Toxoplasma among sheep and goats in Northern Iraq. Veterinary Parasitology: Regional Studies and Reports, p.100264.

16. Ahmed, M.H., Noor, S.K., Bushara, S.O., Husain, N.E., Elmadhoun, W.M., Ginawi, I.A., Osman, M.M., Mahmoud, A.O. and Almobarak, A.O. 2017. Non-alcoholic fatty liver disease in Africa and Middle East: An attempt to predict the present and future implications on the healthcare system. Gastroenterology research, 10(5): 271.

17. Weiss, L.M. and Dubey, J.P. 2009. Toxoplasmosis: A history of clinical observations. International journal for parasitology, 39(8): 895-901.

18. Darwish, M.A., Faris, R., Darwish, N., Shouman, A., Gadallah, M., El-Sharkawy, M.S., Edelman, R., Grumbach, K., Rao, M.R. and Clemens, J.D. 2001. Hepatitis c and cirrhotic liver disease in the Nile delta of Egypt: a community-based study. The American journal of tropical medicine and hygiene, 64(3): 147-153.

19. Geng, Z., Shi, Y., Fang, Y., Li, S. and Liu, L. 2000. Analysis of trace elements in liver, spleen and brain of rats infected with Toxoplasma gondii. Chinese journal of parasitology \& parasitic diseases, 18(6) 347-349.

20. Ghanam, M.E., Shataat, M.A., Monib, M.S., Hassan, A.A. and Younis, A.I. 2001. Evaluation of the role of some parasitic infections as a cause of acute and chronic hepatic diseases. Journal of the Egyptian Society of Parasitology, 31(1): 37-42.

21. Caner, A., Döşkaya, M., Karasu, Z., Değirmenci, A., Guy, E., Kılıç, M., Zeytunlu, M., Francis, J., Bozoklar, A. and Gürüz, Y. 2008. Incidence and diagnosis of active toxoplasma infection among liver transplant recipients in Western Turkey. Liver Transplantation, 14(10): 1526-1532.

22. Ustun, S., Aksoy, U., Dagci, H. and Ersoz, G. 2004. Frequency of toxoplasmosis in patients with cirrhosis. World journal of gastroenterology, 10(3): 452.

23. Alvarado-Esquivel, C., Torres-Berumen, J.L., Estrada-Martínez, S., Liesenfeld, O. and MercadoSuarez, M.F. 2011. Toxoplasma gondii infection and liver disease: a case-control study in a northern Mexican population. Parasites \& vectors, 4(1): 75.

24. El-Henawy, A.A.E.R., Abdel-Razik, A., Zakaria, S., Elhammady, D., Saudy, N. and Azab, M.S. 2015. Is toxoplasmosis a potential risk factor for liver cirrhosis?. Asian Pacific journal of tropical medicine, 8(10): 784-791.

25. Tait, E.D. and Hunter, C.A. 2009. Advances in understanding immunity to Toxoplasma gondii. Memorias do Instituto Oswaldo Cruz, 104(2): 201-210.

26. Sookoian, S. and Pirola, C.J. 2012. Alanine and aspartate aminotransferase and glutamine-cycling pathway: their roles in pathogenesis of metabolic syndrome. World journal of gastroenterology: WJG, 18(29): 3775.

27. He, J.J., Ma, J., Elsheikha, H.M., Song, H.Q., Zhou, D.H. and Zhu, X.Q. 2016. Proteomic profiling of mouse liver following acute Toxoplasma gondii infection. PLoS One, 11(3): p.e0152022.

28. Limdi, J.K. and Hyde, G.M. 2003. Evaluation of abnormal liver function tests. Postgraduate medical journal, 79(932): 307-312.

29. Dawood, M.N. and Mahmood, N.A. 2012. Liver function tests in toxoplasmosis. Annals of the College of Medicine Mosul, 38(2): 68-72. 